7. Reprod. Fert. (1972) 28, 197-206

\title{
SEMINAL PLASMA EFFECTS ON BOVINE ENDOMETRIAL RESPIRATION
}

\author{
E. C. MATHER* AND H. E. DALE \\ * Department of Veterinary Medicine and Surgery, and \\ Department of Veterinary Physiology and Pharmacology, \\ School of Veterinary Medicine, University of Missouri-Columbia, \\ Columbia, Missouri 65201, U.S.A. \\ (Received 14th January 1971)
}

Summary. The oxygen uptake of bovine endometrium was less when perfused with seminal plasma than when perfused with Krebs-Ringer phosphate buffer solution. Dialysing the seminal plasma against KrebsRinger phosphate buffer solution did not alter the depressant action of the seminal plasma. The depressant substance was shown to be partially heat labile.

Variable mineral concentrations were not responsible for the respiratory depression of the endometrium. It was found, however, that calcium is contributed to the seminal plasma in various amounts and that this contribution is made in conjunction with or associated with the nondialysable depressant substance. Calcium does not appear to be tightly bound to the non-dialysable material and its removal does not alter the depressant action.

It was shown that the degree of respiratory depression is related to the dry weight of non-dialysable seminal plasma.

\section{INTRODUCTION}

Seasonal influence on the components of seminal plasma in the bull has been shown by Singh, Mahapatro \& Sadhu (1969) and a seasonal variation in the non-return rate has been shown by Sullivan \& Elliot (1968) and by Salisbury (1968). Shah, Hopwood \& Faulkner (1968) have studied the problem of seminal plasma variation by surgically removing the seminal vesicles and, in so doing, have clarified the contributions of bovine seminal vesicles.

Studies such as these should help to elucidate the effect of seminal plasma on the fertilizing capacity of spermatozoa. In the past, such an effect has frequently been denied since fertilization has been achieved either by use of spermatozoa separated from seminal plasma by centrifugation or by the use of epididymal spermatozoa. Chang (1947) has shown, however, that seminal plasma is important in maintaining high fertility rates when the number of spermatozoa used for an inseminating dose is reduced to a minimum.

The bulk of the inorganic cations in bull seminal plasma is made up of sodium, potassium, calcium and magnesium and mean values have been 
reported by various investigators (Nesmejanova, 1939; Rothschild \& Barnes, 1954; Salisbury \& Cragle, 1956; Cragle, Salisbury \& VanDemark, 1958; Quinn, White \& Wirrick, 1965). The range of means for sodium is from 225 $\mathrm{mg} / 100 \mathrm{ml}$ to $290 \mathrm{mg} / 100 \mathrm{ml}$. Mean potassium values reported by the same five groups of investigators vary more than do sodium values; from $155 \mathrm{mg} / 100$ $\mathrm{ml}$ to $227.8 \mathrm{mg} / 100 \mathrm{ml}$. Rothschild \& Barnes (1954) reported an inverse relationship between sodium and potassium. Mean values for calcium levels in seminal plasma range from $28.0 \mathrm{mg} / 100 \mathrm{ml}$ reported by Salisbury \& Cragle (1956) to $38.6 \mathrm{mg} / 100 \mathrm{ml}$ reported by Quinn et al. (1965). Rothschild \& Barnes (1954) reported a significant correlation of calcium with chloride, citric acid, fructose and total nitrogen. The relationship was such that a knowledge of the concentration of any one of the constituents enabled the average concentration of the other four in the sample to be predicted with fair accuracy. The relationship also suggests a common source for these seminal plasma ingredients. Mean magnesium values of $8.1 \mathrm{mg} / 100 \mathrm{ml}$ have been reported by Quinn et al. (1965) using atomic absorption spectrophotometry; these correspond well with those of Rothschild \& Barnes (1954), who reported $8.5 \mathrm{mg} / 100 \mathrm{ml}$ using chemical methods of analysis.

Constituents of seminal plasma are added to the semen at various locations in various amounts. The cation levels of vesicular secretions have been studied by Quinn et al. (1965), Salisbury \& Cragle (1956) and Cragle et al. (1958). Values for sodium and potassium are similar to those found in seminal plasma, but calcium and magnesium levels are higher. It would appear that the vesicular glands are the chief contributor of calcium in bull seminal plasma. Faulkner, Hopwood \& Wiltbank (1968) reported on the fertility of bulls following vesiculectomy. They found that vesicular glands were not essential for fertility. Their evidence indicated that the absence of vesicular glands caused significant changes in sperm cell morphology, specifically increased secondary abnormalities and decreased primary abnormalities. In addition, total volume and nitrogen concentration decreased. King \& Macpherson (1969) showed no effect on the fertilizing capacity of bovine spermatozoa following vesiculectomy of the bull.

There has been considerable effort since the work of Chang (1951) and Austin (1951) to explore and explain the influence which the female reproductive tract has upon the physiology of the spermatozoa. There has been only scattered effort, however, to explore the converse, the effect of male components upon the reproductive physiology of the female.

It has not been determined to what extent the seminal plasma might enter the uterus of the cow during natural service. It is obviously not a direct deposition as is the case in the boar and the stallion. Its presence in the uterus can be detected, however, by measuring radioactively labelled materials and chemical constituents of the seminal plasma (McDonald, 1969). Hunter \& Hafs (1964) have reported on sperm-coating antigens and described seven different antigens in ejaculated bovine semen; at least five are shared with seminal plasma. Some of these coating antigens are found on spermatozoa from the vas deferens and must, therefore, have been deposited before the contributions of the major accessory sex glands came into contact with the spermatozoa. 
A smooth muscle-stimulating effect of prostaglandins on the uterus has been reported by Bergström, Krabisch \& Sjövall (1960). A haemolytic factor has been demonstrated in bovine seminal plasma by Hunter, Stevens \& Hafs (1963). Matousek \& Petrovska (1969) have reported an antifertilizing substance found in vesicular fluids of bulls. A vitelline-lysing factor in bovine seminal plasma has been reported by Masaki, Sugie \& Otsuki (1968). In addition, Mather \& Dale (1969b) have reported that a substance in seminal plasma of the bull has an inhibitory effect on the respiration of bovine endometrium. The nature of the active substance has not been elucidated except for the fact that sperm cells washed in calcium-free Krebs-Ringer phosphate solution did not exhibit this same depressant effect on endometrial preparations.

Marinov \& Lovell (1968) and Stinson, Weber \& Zemjanis (1962) have reported on the ultrastructure of bovine endometrium. An increase in the number and size of mitochondria as well as a change in internal structure during the latter third of the oestrous cycle was reported. Since it is known that the mitochondria contain enzymes, they associated this finding with an increased or changing metabolic activity within the cells at that time. These changes may be associated with the changes in respiratory activity during the oestrous cycle reported by Mather \& Dale (1969a).

The endoplasmic reticulum, seen as isolated tubules in the earlier part of the cycle, proliferated into large clusters later in the cycle; the authors interpret this finding to indicate an increase in protein synthesis. Cyclic variation was also observed in the structure of the Golgi apparatus (Stinson et al., 1962).

\section{MATERIALS AND METHODS}

Semen was collected from mature bulls ranging in age from 18 months to 7 years. In most cases, it was necessary to collect more than one ejaculate to obtain enough semen for a particular experiment. A minimum of $15 \mathrm{ml}$ of semen was necessary to provide enough seminal plasma for respiratory experiments and mineral determinations.

Before each bull was accepted for use, a screening test for breeding soundness was made according to the procedures outlined by Carrol, Ball \& Scott (1963). This test included a rectal examination of the accessory sexual glands and an evaluation of semen with regard to concentration, motility of spermatozoa, live-dead percentages and morphology of the spermatozoa. Semen was collected both by artificial vagina (natural service) and by electroejaculation. Only the sperm-rich portion of the semen sample was used when electroejaculation was employed.

The semen was centrifuged at $1500 \mathrm{~g}$ for $20 \mathrm{~min}$. After $\mathrm{pH}$ determinations had been made on the seminal plasma, it was stored at $5^{\circ} \mathrm{C}$ until used.

The sample to be dialysed was put into tubing which would retain materials with a molecular weight of 12,000 and higher. Dialysis was carried out at $5^{\circ} \mathrm{C}$ for $12 \mathrm{hr}$ against 2 litres of calcium-free Krebs-Ringer phosphate buffer solution. After $12 \mathrm{hr}$, the solution was replaced with 2 litres of fresh solution and allowed to dialyse for another $12 \mathrm{hr}$ at $5^{\circ} \mathrm{C}$. The material remaining within the dialysis tubing was then used for the experiment. The volume of the dialysed seminal 
plasma was equal to or, in a few cases, slightly more than, the original volume admitted to the tubing.

Just before the experiment, another sample of seminal plasma was placed in a test tube and heated in a water bath at $95^{\circ} \mathrm{C}$ for a period of $15 \mathrm{~min}$. The sample was then cooled to $37^{\circ} \mathrm{C}$ before combining with other tissue.

Other than being maintained at $5^{\circ} \mathrm{C}$, the remaining seminal plasma was not manipulated. This then gave a total of three seminal plasma preparations for each experiment.

Aliquots of seminal plasma and dialysed seminal plasma were frozen until analysis for mineral content could be made.

Sodium and potassium determinations were made on seminal plasma both before and after dialysis. Measurements were made with an internal lithium standard flame photometer. Calcium and magnesium levels were determined both before and after dialysis by atomic absorption spectrophotometry.

All bovine endometrial tissue for this study was obtained from a local abattoir. The interval between slaughter and removal of the uterus was approximately $15 \mathrm{~min}$. The uterus was immediately cooled and taken to the laboratory. The criteria for selection of oestrogenic tissue were similar to those described previously by Mather \& Dale (1969b).

Only tissue under the influence of oestrogens was used in this experiment. The presence on one or both ovaries of a follicle over $15 \mathrm{~mm}$ in diameter and the absence of an active corpus luteum were used as one basis for selection of oestrogenic endometrium (Zemjanis, 1962). Another criterion upon which each reproductive tract was evaluated was the character of the cervical mucus as described by Alliston, Patterson \& Ulberg (1958). This proved to be valuable in that it permitted more critical estimates as to the time of the oestrous cycle.

The $\mathrm{pH}$ of the uterine lumen was recorded as soon as possible after the tissue was taken to the laboratory. This was done with a $\mathrm{pH}$ meter and an electrode which had a length of $16 \mathrm{~cm}$ and an outer diameter of $7 \mathrm{~mm}$. The body of the uterus was incised transversely, the electrode was inserted into the lumen and measurements were taken at various locations within the lumen. After $\mathrm{pH}$ readings were recorded, the uterus was incised longitudinally enabling the endometrium to be stripped from the myometrium. Only endometrium that was at least $2 \mathrm{~cm}$ from the cervix and from the uterotubal junction was used. No differentiation was made between caruncular and intercaruncular tissue. The endometrium was stripped from the previously chilled uterus and placed on a cooled watch glass. At all times after the removal of the tissue from the animal, an attempt was made to keep the temperature of the material low to reduce metabolic activity.

The tissue was cut into long strips approximately $2 \mathrm{~mm}$ in width with a pair of scissors and a scalpel. These strips were weighed and measured into $1 \mathrm{~g}$ $( \pm 0.001 \mathrm{~g})$ aliquots either by trimming off excess tissue or adding more tissue strips.

All respiratory studies were conducted in a Warburg, constant volume, manometric apparatus utilizing the direct method of Warburg (Umbreit, Burris \& Stauffer, 1959). All flasks were incubated at $37^{\circ} \mathrm{C}$ at a shaking rate of $90 / \mathrm{min}$. At least $20 \mathrm{~min}$ were allowed for equilibration, after which readings 
were made at 15-min intervals for $2 \mathrm{hr}$. If a uniform respiratory rate was maintained for $2 \mathrm{hr}$, the first hour's rate was recorded and evaluated.

In the Warburg flask, the endometrial preparation was bathed in calciumfree Krebs-Ringer solution mixed in equal parts with a phosphate buffer adjusted to a $\mathrm{pH}$ of $7 \cdot 4$.

In addition to the tissue and its respective perfusing solution, each Warburg flask contained $0.1 \mathrm{ml} 1.0 \%$ glucose, $0.1 \mathrm{ml} 2.5 \%$ streptomycin sulphate, and $0.2 \mathrm{ml} 5 \mathrm{~N}-\mathrm{KOH}$ in the centre well.

The $\mathrm{pH}$ of the contents of each flask was measured following the incubation period of the experiment and dry weight determinations were made on the contents.

\section{RESULTS}

Table 1 shows the mean respiratory values of tissue incubated in the various perfusing solutions. Since sufficient seminal plasma was not always available, only ten replications were made using dialysed seminal plasma and eleven using heated seminal plasma.

TABLE 1

OXYGEN UPTAKE OF BOVINE ENDOMETRIUM PERFUSED IN VARIOUS SOLUTIONS

\begin{tabular}{c|c|c}
\hline Perfusing solution & $n^{*}$ & Mean \pm S.E. \\
\hline KRP & 15 & $39.9 \pm 1.39$ \\
HSP & 11 & $37.4 \pm 1 \cdot 64$ \\
DSP & 10 & $34 \cdot 7 \pm 1 \cdot 63$ \\
SP & 15 & $33 \cdot 8 \pm 1 \cdot 41$ \\
\hline
\end{tabular}

KRP = Krebs-Ringer phosphate; HSP = heated seminal plasma; DSP = dialysed seminal plasma; $\mathrm{SP}=$ plain seminal plasma.

Values for oxygen uptake expressed in $\mu \mathrm{l} / \mathrm{hr} / \mathrm{g}$ bovine endometrium

* Number of replications upon which the mean is based

It is possible to make six comparisons with the above data (Table 2). The results indicate a highly significant difference between endometrium incubated in a Krebs-Ringer phosphate solution and paired endometrium incubated in seminal plasma, and between endometrium incubated in dialysed seminal plasma and that incubated in Krebs-Ringer phosphate.

Analysis of bovine seminal plasma for sodium, potassium, calcium and magnesium revealed the values shown in Table 3.

Correlation analysis of the four constituents measured in the seminal plasma is presented in Table 4.

The oxygen uptake values of endometrium incubated in unaltered seminal plasma were subtracted from the oxygen uptakes of paired endometrium preparations incubated in Krebs-Ringer phosphate. In all cases, there was a decrease in respiration which was variable in magnitude. In an attempt to relate this depression of respiratory metabolism to some other variable, correla- 
tion coefficients were determined with the sodium, potassium, calcium and magnesium levels in the seminal plasma for each replication of the experiment. The results indicate that, as the calcium content of the seminal plasma increased, the endometrial respiration was proportionately decreased $(P=0 \cdot 02)$. Levels of the other cations, apart from magnesium, did not show any tendency toward a correlation.

A similar analysis was made to determine if a correlation existed between seminal plasma minerals and the decreased respiration observed when tissue was perfused in dialysed seminal plasma. Even though the dialysed seminal

TABLe 2

COMPARISONS OF OXYGEN UPTAKE AT END OF THE FIRST HOUR OF BOVINE ENDOMETRIAL PREPARATIONS INGUBATED IN VARIOUS PERFUSING SOLUTIONS

\begin{tabular}{l|cccc}
\hline \multicolumn{1}{c|}{ Comparison } & $n$ & $\bar{D}$ & $S_{\bar{D}}$ & $t$ \\
\hline 1. KRP versus SP & 15 & $6 \cdot 1$ & $1 \cdot 505$ & $4 \cdot 08^{* *}$ \\
2. KRP versus HSP & 11 & $2 \cdot 1$ & $1 \cdot 859$ & $1 \cdot 10^{\text {ns }}$ \\
3. KRP versus DSP & 10 & $4 \cdot 4$ & $1 \cdot 867$ & $2 \cdot 33^{*}$ \\
4. SP versus HSP & 11 & $2 \cdot 4$ & $1 \cdot 569$ & $1 \cdot 49^{\text {ns }}$ \\
5. SP versus DSP & 10 & $1 \cdot 9$ & $0 \cdot 879$ & $2 \cdot 10^{\text {ns }}$ \\
6. HSP versus DSP & 6 & $1 \cdot 5$ & $2 \cdot 981$ & $0 \cdot 50^{\text {ns }}$ \\
\hline
\end{tabular}

$\bar{D}=$ mean difference of respiratory values; $S_{\bar{D}}=$ standard error of the mean difference; $t=$ Students' $^{t}$ test; $\mathrm{n}=$ number of comparisons.

* $P=0.05 ;{ }^{* *} P=0.005 . \mathrm{ns}=$ not significant.

TABLE 3

GONCENTRATION OF MINERALS IN BOVINE SEMINAL PLASMA

\begin{tabular}{l|r}
\hline \multicolumn{1}{c|}{ Mineral } & \multicolumn{1}{|c}{ Mean \pm S.E. } \\
\hline Sodium & $277.6 \pm 18.4$ \\
Potassium & $149.8 \pm 14.6$ \\
Calcium & $33.9 \pm 7 \cdot 1$ \\
Magnesium & $7.5 \pm 1.5$ \\
\hline
\end{tabular}

Values expressed in $\mathrm{mg} / 100 \mathrm{ml}$.

TABLE 4

CORRELATION GOEFFICIENTS OF $\mathrm{Na}^{+}, \mathrm{K}^{+}, \mathrm{Ca}^{++}$AND $\mathrm{Mg}^{++}$IN BOVINE SEMINAL PLASMA

\begin{tabular}{|c|c|c|c|c|}
\hline & $\mathrm{Na}^{+}$ & $K^{+}$ & $\mathrm{Ca}^{++}$ & $\mathrm{Mg}^{++}$ \\
\hline $\begin{array}{l}\mathrm{Na}^{+} \\
\mathrm{K}^{+} \\
\mathrm{Ca}^{++} \\
\mathrm{Mg}^{++}\end{array}$ & - & $-0.69^{*}$ & $\begin{array}{c}-0.264^{\text {ns }} \\
-0.145^{\text {ns }} \\
-\end{array}$ & $\begin{array}{c}-0.136^{\text {ns }} \\
0.143^{\text {ns }} \\
0.829^{* *} \\
-\end{array}$ \\
\hline
\end{tabular}


plasma had its calcium almost entirely removed, i.e. the concentration reduced from a $33.98 \mathrm{mg} / 100 \mathrm{ml}$ to $1.60 \mathrm{mg} / 100 \mathrm{ml}$, there was still a positive correlation $(P=0.02)$ between the magnitude of depression and the calcium concentration in the original seminal plasma.

Dry weight determinations were made following incubation on all bovine endometrium preparations and their respective perfusing solutions. The average dry weight of control samples of endometrium was $0.1686 \mathrm{~g} / 1.000 \mathrm{~g}$ wet weight or $16.86 \%$. The dry weight of endometrium incubated in Krebs-Ringer phosphate was not significantly correlated with rate of oxygen uptake. The mean total dry weight of bovine endometrium perfused in seminal plasma was $0.2189 \mathrm{~g}$. The dry weight of the seminal plasma, $5.03 \mathrm{~g} / 100 \mathrm{ml}$, was calculated by subtracting the average dry weight of $1.0 \mathrm{~g}$ of endometrium. A correlation analysis between respiration and the total dry weight of endometrium plus seminal plasma showed a tendency toward a negative correlation.

Similar correlation analysis between respiration and total dry weight of bovine endometrium in dialysed seminal plasma showed a significant and negative correlation $(P=0.05)$; as dry weight increased, respiration decreased. The estimated mean dry weight of dialysed seminal plasma was $1.95 \mathrm{~g} / 100 \mathrm{ml}$.

The mean weight of heated seminal plasma together with the endometrium was $0.2138 \mathrm{~g}$. This value was close to that, $0.2189 \mathrm{~g}$, for seminal plasma and endometrium. No correlation was evident between the respiration of endometrium and the dry weight of heated seminal plasma.

The mean $\mathrm{pH}$ of fifteen bovine seminal plasma samples immediately after removal of the spermatozoa was 6.6. The mean luminal $\mathrm{pH}$ of fifteen bovine uteri used in the sliced endometrial experiments was 6.43 with a standard error of the mean of $0 \cdot 03$. Neither the initial luminal $\mathrm{pH}$ nor the $\mathrm{pH}$ of the seminal plasma was significantly correlated with respiration of the tissue.

The $\mathrm{pH}$ was determined on the endometrial preparations at the end of the incubation period. Mean $\mathrm{pH}$ values for endometrial preparations incubated in Krebs-Ringer phosphate, dialysed seminal plasma, seminal plasma and heated seminal plasma were $7.01,7.01,6.93$ and 6.89 , respectively. There was no significant difference between them. The final $\mathrm{pH}$ was not significantly correlated with respiration in any of the four groups.

\section{DISCUSSION}

Baird \& McDonald (1964) reported mean values of 0.18 to $0.52 \mu$ l oxygen uptake/mg dry weight/hr for caruncular tissue measured at different periods of gestation and mean values of 0.23 to $0.49 \mu$ oxygen uptake/mg dry weight $/ \mathrm{hr}$ for cotyledonous tissue. Their reports compare favourably with the results of this experiment when all the data are converted to a dry weight basis. Baird \& McDonald (1964) discussed the higher respiratory rates observed in human endometrium and attributed the difference to a negative correlation of metabolic rate and body size.

Sodium, potassium, calcium and magnesium levels of bovine seminal plasma correspond well with previous reports. Potassium and magnesium levels are measurably, but not significantly, lower. The difference may be due to different 
methods of collection used by various investigators. Our values were measured in samples obtained both by natural collection and by electroejaculation. As Lutwak-Mann \& Rowson (1953) have pointed out, the composition of semen varies considerably, depending upon the portion of the electroejaculated sample analysed. Their findings indicated that mineral levels in nearly all cases were lower in the pre-sperm fraction of the collection. Values reported in this work apply to the sperm-rich portions of the ejaculate in the case of electroejaculation and to the complete ejaculate in the case of natural service. It was not always possible to effect a complete separation of the pre-sperm from the sperm-rich portions of the ejaculate, so there may have been a slight lowering of the mean values.

The finding by Rothschild \& Barnes (1954) that there is an inverse relationship between concentrations of sodium and potassium in bovine seminal plasma is substantiated by this investigation. Rothschild \& Barnes (1954) also reported a degree of correlation between calcium and magnesium levels, and data presented here confirm a significant interrelationship between these two cations.

It has been shown that the respiration of bovine endometrium is depressed when perfused in seminal plasma and in dialysed seminal plasma. Most of the effect on endometrial respiration was exerted by a substance with a molecular weight of over 12,000. Variations in the mineral concentrations found in seminal plasma are apparently not responsible for the depressant effect. Analysis of the seminal plasma after dialysis in calcium-free Krebs-Ringer phosphate showed the calcium content to be nil and the other measured cations were present in amounts comparable to concentrations found in the buffer solution. Despite the fact that the activity is not removed by dialysis, the possibility of protein binding of other unmeasured depressant minerals cannot be entirely discounted, nor has the presence of a non-specific protein respiratory inhibition been completely eliminated.

The nature of the depressant material was further characterized by heating the seminal plasma. This procedure resulted in partial removal of the depressant action; heated seminal plasma lowered mean respiration by $6.3 \%$ rather than the significant $15.5 \%$ caused by intact seminal plasma.

Even though minerals did not appear to be the active agents in respiratory depression, their correlation with such a depression revealed a significant relationship. The calcium concentration in bovine seminal plasma was significantly correlated with the degree of respiratory depression, and this relationship was maintained even after dialysis of the seminal plasma, i.e. the respiratory depression was still correlated with the original calcium content even after its removal. The evidence suggests that a non-dialysable substance was contributed to the seminal plasma in various amounts and that this contribution was made in conjunction with the calcium contribution. The active material did not appear to be tightly bound to calcium ions since very little calcium was found in the dialysed seminal plasma. Calcium is added to bovine seminal plasma primarily by the vesicular gland, and it is also known that the vesicular gland contributes considerable protein and nitrogenous material. The vesicular gland and the ampullar gland are very similar histologically and embryologically in the bull and the strong likelihood exists that these two organs are the 
main contributors of macromolecules capable of depressing endometrial respiration.

A significant and negative correlation was present when the dry weight of endometrium and dialysed seminal plasma was compared to oxygen uptake. A similar tendency was observed with seminal plasma-perfused endometrium.

There is no correlation between Krebs-Ringer phosphate-perfused endometrial dry weight or heated seminal plasma-perfused endometrial dry weight and oxygen uptake. The fact that this correlation existed with dialysed seminal plasma, the dry weight of which is low, implies the presence of a very 'influential' macromolecule.

The mechanism by which respiration of endometrium is altered by seminal plasma is unknown. As Stinson et al. (1962) and Marinov \& Lovell (1968) have shown, components of the endometrial cells are continually changing throughout the oestrous cycle. These components, the cell wall, the mitochondria and other structural inclusions, are all capable of carrying on a respiratory process. The component or components involved in the respiratory changes noted above were not determined in this research, nor is it known what effect seminal plasma may have on anaerobic glycolysis of endometrium.

Ericsson (1969), in a report on the relationship between capacitation and the presence of eosinophil leucocytes, suggested that the presence of semen in the female reproductive tract triggers a foreign body response, that antigens coat spermatozoa and cause an eosinophilic chemotaxis and that this, in turn, is followed by removal of the antigen or antigen-antibody complex. His report does not involve cattle but does present an example of an interaction between the female and a large molecule from the male.

It is also known that the concentrations of amino acids and proteins in the uterine fluid change during the oestrous cycle (Fahning, Schultz \& Graham, 1967). Krishnan \& Daniel (1967) have associated such changes with regulation and development of the blastocyst. These authors believe there is a macromolecule 'regulator' involved in luminal protein changes. Since bovine uteri can accept and harbour fertilized ova from another female, it might be argued that a 'regulator' from the bull is not needed for gestation but only for fertilization. Conversely, an overabundance of such factors in the seminal plasma might have a detrimental effect. This type of action has been reported by Abney \& Williams (1970) who showed that intrauterine deposition of seminal plasma 'decapacition factor' inhibited sperm capacitation in the rabbit.

\section{ACKNOWLEDGMENT}

This investigation was supported in part by Veterinary Medicine Research Council Grant 190.

\section{REFERENCES}

ABNEY, T. O. \& WiLliams, W. L. (1970) Inhibition of sperm capacitation by intrauterine deposition of seminal plasma decapacitation factor. Biol. Reprod. 2, 14.

Alliston, C. W., Patterson, T. B. \& Ulberg, L. G. (1958) Crystallization patterns of cervical mucus as related to estrus in beef cattle. F. Anim. Sci. 17, 322 .

Austin, C. R. (1951) Observation of the penetration of the sperm into the mammalian egg. Aust. $\mathcal{F}$. Scient. Res. B4, 581. 
Batrd, E. R. \& McDonald, L. E. (1964) In vitro oxygen uptake by the maturing bovine placenta. Am. F. vet. Res. 25, 367.

Bergström, S., Krabisch, L. \& Sjövall, J. (1960) Smooth muscle stimulating factors in ram semen. Acta chem. scand. 14, 1706.

Carrol, E. J., Ball, L. \& Scott, J. A. (1963) Breeding soundness in bulls-a summary of 10,940 examinations. 7. Am. vet. med. Ass. 142, 1105.

Chang, M. C. (1947) Effects of testis hyaluronidase and seminal fluids on the fertilizing capacity of rabbit spermatozoa. Proc. Soc. exp. Biol. Med. 66, 51.

Chang, M. G. (1951) Fertilizing capacity of spermatozoa deposited into the Fallopian tubes. Nature, Lond. 168, 697.

Cragle, R. G., Salisbury, G. W. \& VanDemark, N. L. (1958) Sodium, potassium, calcium and chloride distribution in bovine semen. F. Dairy Sci. 41, 1267.

ERICsson, R. J. (1969) Capacitation in vitro of rabbit sperm with mule eosinophils. Nature, Lond. 221, 568.

Fahning, M. L., Schultz, R. H. \& Graham, E. F. (1967) The free amino acid content of uterine fluids and blood serum in the cow. 7. Reprod. Fert. 13, 229.

FaUlkner, L. C., Hopwood, M. L. \& Wiltbank, J. N. (1968) Seminal vesiculectomy in bulls. II. Seminal characteristics and breeding trials. 7 . Reprod. Fert. 16, 179.

Hunter, A. G. \& Hafs, H. D. (1964) Antigenicity and cross-reactions of bovine spermatozoa. $\mathcal{F}$. Reprod. Fert. 7, 357.

Hunter, A. G., Stevens, K. R. \& Hafs, H. D. (1963) Characteristics of the hemolytic factor in bovine seminal plasma. 7. Dairy Sci. 46, 618.

King, G. J. \& MacPherson, J. W. (1969) Influence of seminal vesiculectomy on bovine semen. $\mathcal{F}$. Dairy Sci. 52, 1837.

KRISHNAN, R. S. \& DANIEL, J. C. (1967) "Blastokinin": Inducer and regulator of blastocyst development in the rabbit uterus. Science, N.Y. 158, 490.

Lurwak, M. \& Rowson, L. E. A. (1953) The chemical composition of the pre-sperm fraction of bull ejaculate obtained by electrical stimulation. F. agric. Sci., Camb. 43, 131.

McDonald, L. E. (1969) Veterinary endocrinology. Lea \& Febiger, Philadelphia, Pa.

Marinov, U. \& Lovelt, J. E. (1968) Cytology of the bovine uterine epithelium during the estrous cycle. Am. J. vet. Res. 29, 13.

Masaki, J., Sugie, K. \& Otsuki, K. (1968) Lytic action of bovine seminal plasma on vitellus of mammalian eggs. Proc. VIth int. Cong. Anim. Reprod. A.I. 1, 549.

Mather, E. C. \& Dale, H. E. (1969a) Respiratory studies of bovine endometrial preparations. $\mathcal{F}$. Reprod. Fert. 18, 174.

Mather, E. C. \& Dale, H. E. (1969b) Respiratory studies of bovine spermatozoa and endometrial preparations. 7. Reprod. Fert. 20, 401.

Matousek, J. \& Petrovska, E. (1969) Antifertilizing effect of the seminal vesicle fluid of bulls on females. F. Reprod. Fert. 20, 189.

Nesmejanova, T. N. (1939) The K, Na, and Ca content of the sperm and accessory secretions of the bull and ram. Anim. Breed. Abstr. 7, 204.

Quinn, P. J., Whrte, I. G. \& Wirrick, B. P. (1965) Studies of the distribution of the major cations in semen and male accessory secretions. F. Reprod. Fert. 10, 379.

Rothschild (LORD) \& Barnes, H. (1954) Constituents of bull seminal plasma. F. exp. Biol. 31, 561.

Salisbury, G. W. (1968) Fertilizing ability and biological aspects of sperm storage in vitro. Proc. VIth int. Cong. Anim. Reprod. A. I. 2, 1189.

Salisbury, G. W. \& CRAGLe, R. G. (1956) Freezing point depression and mineral levels of fluids of the ruminant male reproductive tract. Proc. 3rd int. Cong. Anim. Reprod. 1, 25.

Shah, B. A., Hopwood, M. L. \& Faulkner, L. C. (1968) Seminal vesiculectomy in bulls. I. Seminal biochemistry. 7. Reprod. Fert. 16, 171.

Singh, B., Mahapatro, B. B. \& Sadhu, D. P. (1969) Chemical composition of cattle and buffalo spermatozoa and seminal plasma under different climatic conditions. F. Reprod. Fert. 20, 175.

Stinson, A. W., Weber, A. F. \& Zemjanis, R. (1962) The bovine endometrium; an electron microscopic study. Am. 7. vet. Res. 23, 1164.

Sullivan, J. J. \& Elliotr, F. I. (1968) Season and fertility in artificial insemination. Prod. VIth int. Cong. Anim. Reprod. A.I. 1, 329.

Umbreit, W. W., Burris, R. H. \& Stauffer, J. F. (1959) Manometric techniques. Burgess Publishing Co., Minneapolis.

ZEJAMNIS, R. (1962) Diagnostic and therapeutic techniques in animal reproduction. Williams \& Wilkins, Baltimore. 